AperTO - Archivio Istituzionale Open Access dell'Università di Torino

\title{
Linguistic laws of brevity: conformity in Indri indri
}

\section{This is a pre print version of the following article:}

Original Citation:

Availability:

This version is available http://hdl.handle.net/2318/1780301

since 2022-01-24T09:50:54Z

Published version:

DOI:10.1007/s10071-021-01495-3

Terms of use:

Open Access

Anyone can freely access the full text of works made available as "Open Access". Works made available under a Creative Commons license can be used according to the terms and conditions of said license. Use of all other works requires consent of the right holder (author or publisher) if not exempted from copyright protection by the applicable law. 


\title{
2 Linguistic laws of brevity: conformity in Indri indri
}

\author{
3 Daria Valente ${ }^{1}$ (1) $\cdot$ Chiara De Gregorio $^{1} \cdot$ Livio Favaro $^{1} \cdot$ Olivier Friard $^{1} \cdot$ Longondraza Miaretsoa $^{1} \cdot$ Teresa Raimondi $^{1}$. \\ 4 Jonah Ratsimbazafy ${ }^{2} \cdot$ Valeria Torti ${ }^{1} \cdot$ Anna Zanoli $^{1} \cdot$ Cristina Giacoma $^{1} \cdot$ Marco Gamba $^{1}$
}

5 Received: 29 September 2020 / Revised: 23 January 2021 / Accepted: 19 February 2021

6 (c) The Author(s), under exclusive licence to Springer-Verlag GmbH, DE part of Springer Nature 2021

\begin{abstract}
7 Abstract
8 Vocal and gestural sequences of several primates have been found to conform to two general principles of information 9 compression: the compensation between the duration of a construct and that of its components (Menzerath-Altmann law) 10 and an inverse relationship between signal duration and its occurrence (Zipf's law of abbreviation). Even though Zipf's $\Delta \mathbf{\Delta Q 1}$ 11 law of brevity has been proposed as a universal in animal communication, evidence on non-human primate vocal behavior 12 conformity to linguistic laws is still debated, and information on strepsirrhine primates is lacking. We analyzed the vocal 13 behavior of the unique singing lemur species (Indri indri) to assess whether the song of the species shows evidence for 14 compression. As roars have a chaotic structure that impedes the recognition of each individual utterance, and long notes are 15 usually given by males, we focused on the core part of the song (i.e., the descending phrases, composed of two-six units). Our results indicate that indris' songs conform to Zipf's and Menzerath-Altmann linguistic laws. Indeed, shorter phrases are more likely to be included in the song, and units' duration decrease at the increase of the size of the phrases. We also found that, despite a sexual dimorphism in the duration of both units and phrases, these laws characterize sequences of both males and females. Overall, we provide the first evidence for a trade-off between signal duration and occurrence in the vocal behavior of a strepsirrhine species, suggesting that selective pressures for vocal compression are more ancestral than previously assumed within primates.
\end{abstract}

\section{Keywords Vocal communication · Primates $\cdot$ Linguistic laws $\cdot$ Language evolution $\cdot$ Compression}

\section{Introduction}

Investigating the statistical universals that underpin the evolution of vocal complexity is essential to throw light on the origins of linguistic abilities. Accordingly, comparative studies are needed to assess whether the core features or universals of human vocal communication are shared with other species (Savage et al. 2015). Some of those are likely to have evolved during primate evolution and be linked with shared ancestry. Being non-human primates our closest living relatives, their vocal communication systems have often been regarded as the best model to understand which selective pressures lead to the uniqueness of human language

Daria Valente

daria.valente@unito.it

1 Dipartimento Di Scienze Della Vita E Biologia Dei Sistemi, Università Degli Studi Di Torino, Torino, Italia

2 Groupe D'Étude Et de Recherche Sur Les Primates de Madagascar (GERP), Antananarivo, Madagascar
(Fedurek and Slocombe 2011). Indeed, different crucial aspects underlying human vocal behavior shape the acoustic communication systems of other primates (Leroux and Townsend 2020). For example, previous studies investigated the ability to combine single components into larger structures and their referentiality (Pan troglodytes: Slocombe and Zuberbühler 2005; Pan paniscus: Clay and Zuberbühler 2009; Cercopithecus campbelli: Ouattara et al. 2009; Callicebus nigrifrons: Cäsar and Zuberbühler 2012), the turntaking among individuals (Indri indri: Gamba et al. 2016; Ateles geoffroyi: Briseño-Jaramillo et al. 2018; Macaca fuscata: Katsu et al. 2019), and the presence of rhythmicAQ4 patterns (Indri indri: Gamba et al. 2016; De Gregorio et al. 2019; Tarsius spectrum gurskyae: Clink et al. 2019).

To date, all the human languages tested have been found to adhere to coding efficiency rules (Piantadosi et al. 2011). In particular, they adhere to the Zipf's Law of brevity (1936, 1945, 1949) and the Menzerath-Altmann Law (Altmann 1980): two postulates proposing that the informative elements are condensed as the result of selective pressures

\begin{tabular}{|l|l|l|l|l|}
\hline Journal : Large 10071 & Article No : 1495 & Pages : 10 & MS Code : 1495 & Dispatch : 24-2-2021 \\
\hline
\end{tabular}


for (i) coding efficacy maximization and (ii) code length minimization (Ferrer-i-Cancho et al. 2013). According to Zipf's law, the element's length and frequency of use are inversely related (Ferrer-i-Cancho et al. 2013), while Menzerath-Altmann law suggests that the longer the size of the construction, the shorter that of its components (Altmann 1980). Compression has been hypothesized to represent a universal principle in animal behavior (Ferrer-i-Cancho et al. 2013). Indeed, evidence for conformity to compression laws is widespread across taxa: from bottlenose dolphins' whistle sequences (Tursiops truncatus: Ferrer-i-Cancho and McCowan 2012) and surface behavioral patterns (Ferrer-iCancho and Lusseau 2009) to avian species' vocal behavior, as in Carolina chickadee (Poecile carolinensis: Freeberg and Lucas 2012), and the African penguin (Spheniscus demersus: Favaro et al. 2020) display songs. Zipf's law of brevity also seems to define bats short-range communication (Luo et al. 2013), and Demartsev and colleagues (2019) have recently found that hyrax (Procavia capensis) vocal repertoire shows a sexually dimorphic signal optimization.

Studies of non-human primate vocal behavior showed mixed evidence for conformity with the above-mentioned laws. Indeed, besides humans (Zipf 1945; 1949; Strauss et al. 2007), vocalizations of the Formosan macaque (Macaca cyclopis: Semple et al. 2010, 2013), geladas (Theropithecus gelada: Gustison et al. 2016), eastern chimpanzees (Pan troglodytes schweinfurthii: Fedurek et al. 2017), and mountain gorillas (Gorilla beringei beringei: Watson et al. 2020), as well as the gestural communication of western gorillas (Gorilla gorilla gorilla: Genty and Byrne 2010) and chimpanzees (Heesen et al. 2019), have shown evidence for compression. Conversely, the vocal repertoires of at least two new world primate species have been found to deviate from the pattern predicted by compression principles (Callithrix jacchus, Cacajao melanocephalus: Bezerra et al. 2011). However, a successive study found that the common marmoset short-distance calls conform to Zipf's law (Ferreri-Cancho and Hernández-Fernández 2013).

While the use of acoustic sequences is widespread across species, within primates (Kershenbaum et al. 2016), a peculiarity is represented by the so-called "singing primates" (Geissmann 2000), which belong to four primate families (i.e., Hylobatidae, Indriidae, Tarsiidae, Pitheciidae). A few species from these families show the rare ability to communicate through songs (Haimoff 1986). Among those species, adherence to Zipf's law of brevity has been recently found in the songs of Müller's Bornean (Hylobates muelleri: Clink et al. 2020a, b) and crested gibbons (Nomascus nasutus, Nomascus concolor: Huang et al. 2020).

A further shared feature of speech prosody in human communication is the lengthening of the last segment preceding the pause (final lengthening; Lindblom and Sundberg 2007). A parallel can be traced with recent findings on two singing primates, the Cao-vit gibbon and the western blackcrested gibbon. Males of both species emit stereotyped vocal sequences, where more extended units are more likely to be given at the end rather than at the beginning of a sequence (Nomascus concolor, Nomascus nasutus: Huang et al. 2020).

Semple et al. (2010) seminal work on the Formosan macaque suggested the existence of common ground between the communicative systems of both human and non-human primates, particularly regarding the presence of common rules governing signal duration and occurrence. The authors also suggested that comparable evolutionary forces may have led to increased coding efficiency in primate vocal behavior (Semple et al. 2010). Therefore, considering the ongoing debate about the presence of tradeoffs between signal duration and occurrence in non-human primate sequences, research on previously ignored species is necessary. Within the apes' superfamily, Hominidae diverged from the Hylobatidae family 13-33 million years ago (Glazko and Nei 2003), while lemurs diverged more than 70 million years ago (Herrera and Dàvalos 2016). Thus, the investigation of the only singing species among lemurs significantly broadens our perspective on non-human primate conformity to linguistic laws. Indri (Indri indri) is the only singing lemur species (Haimoff 1986). Indris are genetically monogamous (Bonadonna et al. 2014, 2019) and live in small family groups made of the reproductive pair and their offspring (Torti et al. 2017). Each group occupies and defends an exclusive territory (Bonadonna et al. 2017) mainly using loud and complex vocal sequences (i.e., songs; Torti et al. 2013). Since territories are stable over time (Bonadonna et al. 2020), songs also mediate intra- and inter-group spatial dynamics across years (Bonadonna et al. 2020). Besides an introductory sequence (comprising roars and long notes; Pollock 1986; Thalmann et al. 1993; Sorrentino et al. 2013) indris' songs are made of several discrete vocal units (Gamba et al. 2011, 2016) organized in phrases. Those sequences, also called descending phrases because of a frequency pattern declining along with the phrase (Thalmann et al. 1993; Sorrentino et al. 2013; Gamba et al. 2016), constitute the core part of indris' song, can include from two to six units (Thalmann et al. 1993; Giacoma et al. 2010; Gamba et al. 2016), and their organization is sexually dimorphic (Zanoli et al. 2020). Songs can be emitted as duets-when only the members of the reproductive pair sing together-or as choruses when one or more non-reproductive members join the parents when singing. All the individuals within a family group, aged one year or above, can join the chorus (Torti et al. 2018; De Gregorio et al. submitted R1).

By investigating the structure of phrases the indris gave during the song, we aimed to understand whether the vocal output of this species is subject to selective pressures for information compression. Specifically, we measured (i) 
whether indri phrases conform to the Zipf's law of brevity but, as evidence on other species is blended (Huang et al. 2020; Clink et al. 2020a, b), we did not formulate a precise prediction. Moreover, we investigated (ii) whether the structure of phrases conforms to the Menzerath-Altmann law, expecting that, in line with findings on most of the other primate species tested to date (geladas: Gustison et al. 2016; chimpanzee: Fedurek et al. 2017; gibbons: Huang et al. 2020; Clink et al. 2020), the higher the number of units included in a phrase, the shorter the units' duration. Finally, we investigated (iii) the final lengthening, predicting that the last unit within a phrase would be longer than the previous ones, as demonstrated in humans (Lindblom and Sundberg 2007) and more recently in two singing primate species (Huang et al. 2020).

\section{Methods}

\section{Data collection and analysis}

We recorded spontaneous songs of ten indri groups populating the Maromizaha Forest ( $\left.18^{\circ} 56^{\prime} 49^{\prime \prime} \mathrm{S}, 48^{\circ} 27^{\prime} 53^{\prime \prime} \mathrm{E}\right)$ in Madagascar. Data were collected in the field from 2009 to 2020, using solid-state recorders (Sound Devices 702, Olympus S100 and LS05, Tascam DR-100, DR-40, and DR-05, or Zoom H5) connected to a Sennheiser (ME 66 and ME 67) or AKG Acoustics (CK 98) shotgun microphones (sampling rate $44.1 \mathrm{kHz}, 16$-bit resolution). When recording the songs, thanks to the use of the focal animal sampling (Altmann 1974) and that of natural marks, we were able to attribute each vocalization to its actual emitter.

Indris' songs include the participation of at least two individuals, we edited the songs using Praat 6.0.28 (Boersma and Weenink 2017) and manually selected and extracted the fundamental frequency contour of each indri's contribution to the songs (all the emissions of a particular individual; De Gregorio et al. 2019). Following the methodology previously described in Gamba et al. (2016) and De Gregorio et al. (2019), we then identified and labeled the descending phrases based on the number of elements they included (a phrase can include from two to six units Thalmann et al. 1993; Giacoma et al. 2010; Gamba et al. 2016); for instance, we labeled a phrase including four units as a $\mathrm{DP}_{4}$ (Fig. 1).

We identified 8838 phrases $\left(4127 \mathrm{DP}_{2}, 3765 \mathrm{DP}_{3}, 900\right.$ $\mathrm{DP}_{4}, 46 \mathrm{DP}_{5}$ ), isolated from 683 songs and 1534 individual contributions emitted by 53 individuals ( 28 males: 11 dominant males and 17 non-dominant males; 25 females: 11 dominant adult females, 14 non-dominant females). We annotated the number of units constituting each phrase (phrase size), the number of phrases included in each individual contribution to the song (contribution size), the duration of every single unit within the phrase, and the total duration of the phrase (Fig. 1). We then estimated the proportion of each phrase type in each individual contribution to the songs (phrase proportion, given by the ratio between the number of phrases of a certain type and the total number of phrases; Fig. 1) for all songs recorded between 2012 and 2020 . Using the lme 4 package (Bates et al. 2015) in R ( $\mathrm{R}$ Core Team 2019, version 3.6.1), we built a total of seven generalized linear mixed models (GLMMs): two models were used to investigate the phrase proportion, two to investigate the phrase duration, three to assess the unit duration variation (see Online Resource 2 ). For all models, we verified the absence of collinearity among predictors by inspecting the variance inflation factors (vif package, Fox and Weisberg 2011). Through a likelihood ratio test (Dobson 2002), we then verified the significance of a full model (including both the fixed and random effects) against a null model (comprising the

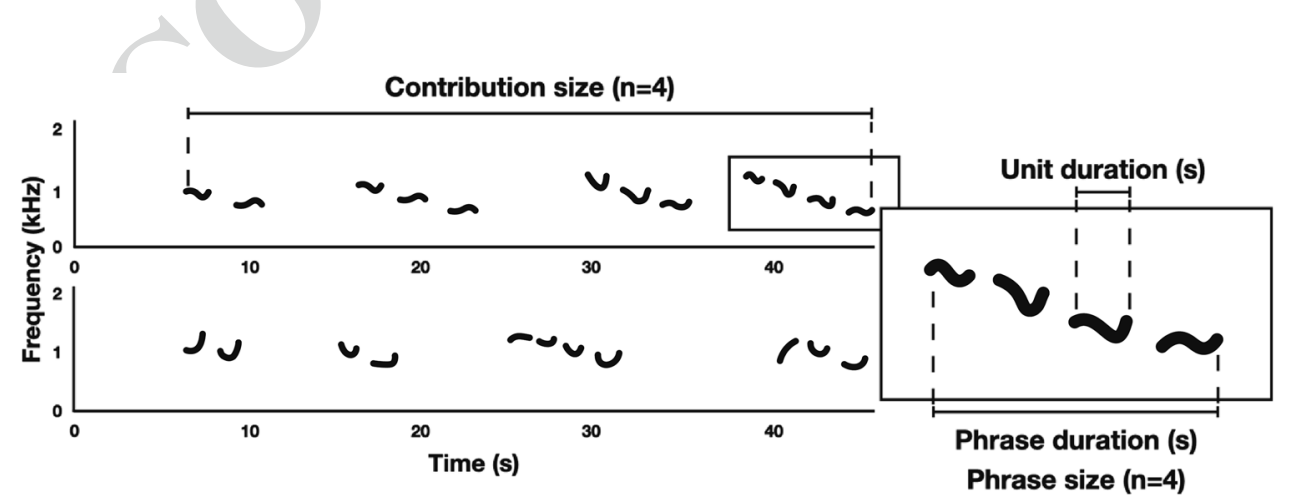

Fig. 1 Schematic representation of the spectrogram (time (s) on the $\mathrm{x}$-axis, frequency $(\mathrm{kHz})$ on the $\mathrm{y}$-axis) of the isolated fundamental frequency of a male (upper) and a female (lower) indri. A descending phrase including four units $\left(\mathrm{DP}_{4}\right)$ is exemplified, to describe acoustic parameter collection of contribution size (in terms of the number of phrases included in an individual contribution), phrase duration (s) and size (in terms of the number of units included in a phrase), unit duration (s). The ratio between the number of a phrase of a certain type and the total number of phrases represents the phrase proportion (i.e., the proportion of the two $\mathrm{DP}_{3}$ in the male contribution represents the 50\%). The spectrogram was generated in R, using the Seewave package (Seur and Aubin 2008)

\begin{tabular}{|l|l|l|l|l|}
\hline Journal $:$ Large $\mathbf{1 0 0 7 1}$ & Article No : 1495 & Pages : 10 & MS Code : 1495 & Dispatch : 24-2-2021 \\
\hline
\end{tabular}


Fig. 2 Density plot representing the proportion of the various phrase types included in the individual contributions to the song, for both sexes. b Density plot representing and the variation of the phrase duration in relation to the type of the phrase for both sexes. Plots were generated in $\mathrm{R}$, using the ggplot 2 package (Wickham 2016) case, data met the assumptions required (Anderson-Darling normality test).

\section{Results}

\section{Phrase proportion}

Indris' songs included a similar proportion of phrases composed of two and three units $\left(\mathrm{DP}_{2}:\right.$ mean $\pm \mathrm{sd}=0.471 \pm 0.220$; $\mathrm{DP}_{3}$ : mean $\left.\pm \mathrm{sd}=0.485 \pm 0.200\right)$, higher than that of longer phrases $\left(\mathrm{DP}_{4}\right.$ : mean $\pm \mathrm{sd}=0.255 \pm 0.164 ; \mathrm{DP}_{5}$ : mean $\pm s d=0.193 \pm 0.191$; Fig. $2 a)$. This is supported by the results of the GLMMs, that indicated an effect of the phrase size on its occurrence, where the larger the phrases size, the smaller their proportion into the songs (full vs. null: $\chi^{2}=447.459, d f=4, p<0.001$; Table 1$)$. Conversely, we did not detect a difference in the frequency of occurrence between phrases composed of two and three units nor between phrases including four and five units (Table 1). When considering the emitter's sex, we found that females and males showed only slightly differences in the proportion of phrases included in their songs (mean $\pm \mathrm{sd}$; $\mathrm{DP}_{2}$, males $0.488 \pm 0.235$; females: $0.453 \pm 0.202$; $\mathrm{DP}_{3}$, males: $0.498 \pm 0.205$; females: $0.471 \pm 0.193 ; \mathrm{DP}_{4}$, males: $0.295 \pm 0.153$; females: $0.233 \pm 0.167 ; \mathrm{DP}_{5}$, males: $0.213 \pm 0.208$; females: $0.180 \pm 0.181$; Fig. $2 a)$. As indicated by the model including the interaction between sex and phrase type, we did not detect a significant effect of the sex on the phrase occurrence for any of the phrase types (full versus null: $\chi 2=452.881, d f=7, p<0.001$; males versus females: estimate $=-0.005, \mathrm{SE}=0.024, t$ value $=-0.224$, $p=0.824$; see Table 1; Fig. 2a).

\section{Phrase duration}

Our results also indicated that the larger the phrase size, the longer its duration (full versus null: $\chi^{2}=18,305.460$,

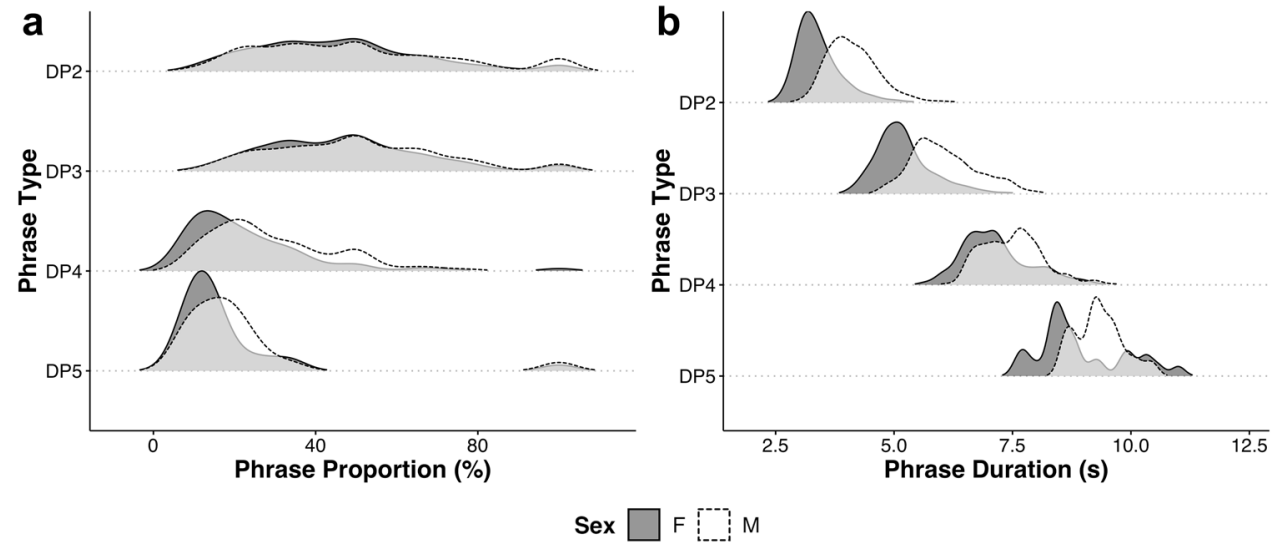


Table 1 Results of the Tukey test for the effect of the descending phrase type (left) and for the interaction including sex and phrase type (right) on the proportion of each phrase type (Anderson-Darling Normality test: $A=32.669$, $p<0.001$ ) included in a contribution

\begin{tabular}{|c|c|c|c|c|c|c|c|c|c|}
\hline \multirow[t]{2}{*}{ Phrase type } & \multicolumn{4}{|c|}{ Proportion } & \multirow{2}{*}{$\begin{array}{l}\text { Phrase type* } \\
\text { sex }\end{array}$} & \multicolumn{4}{|c|}{ Proportion } \\
\hline & Estimate & SE & $z$ value & $p$ value & & Estimate & SE & $z$ value & $p$ value \\
\hline DP3-DP2 & 0.014 & 0.008 & 1.818 & 0.238 & DP2 (M vs F) & -0.009 & 0.024 & -0.224 & 1.000 \\
\hline DP4-DP2 & -0.190 & 0.010 & -18.552 & $<0.001$ & DP3 (M vs F) & -0.009 & 0.024 & -0.379 & 1.000 \\
\hline DP5-DP2 & -0.245 & 0.031 & -7.956 & $<0.001$ & DP4 (M vs F) & 0.037 & 0.028 & 1.348 & 0.841 \\
\hline DP4-DP3 & -0.205 & 0.010 & -20.008 & $<0.001$ & DP5 (M vs F) & 0.026 & 0.065 & 0.405 & 1.000 \\
\hline DP5-DP3 & -0.260 & 0.031 & -8.428 & $<0.001$ & - & - & - & - & - \\
\hline DP5-DP4 & -0.054 & 0.031 & -1.755 & 0.267 & - & - & - & - & - \\
\hline
\end{tabular}

Statistically significant values are indicated in bold

$M$ males, $F$ females, DP2 Descending Phrase including two units, DP3 Descending Phrase including three units, DP4 Descending Phrase including four units, DP5 Descending Phrase including five units $d f=3, p<0.001)$. Indeed, with a mean duration of $3.736 \pm 0.630 \mathrm{~s}, \mathrm{DP}_{2}$ resulted significantly shorter than all other phrases (Fig. $2 b$; mean \pm SD: $\mathrm{DP}_{3}=5.591 \pm 0.791 \mathrm{~s}$; $\mathrm{DP}_{4}=7.277 \pm 0.743 \mathrm{~s} ; \mathrm{DP}_{5}=9.102 \pm 0.804 \mathrm{~s} ; \mathrm{DP}_{3}$ resulted significantly shorter than both $\mathrm{DP}_{4}$ and $\mathrm{DP}_{5}$ while $\mathrm{DP}_{4}$ were shorter than $\mathrm{DP}_{5}$ (Table 2). We also found that phrase duration varies according to the sex of the emitter, where male phrases are longer than female ones (mean \pm sd; $\mathrm{DP}_{2}$, males: $4.126 \pm 0.550 \mathrm{~s}$; females: $3.405 \pm 0.489 \mathrm{~s}$; $\mathrm{DP}_{3}$, males: $6.073 \pm 0.707 \mathrm{~s}$; females: $5.201 \pm 0.621 \mathrm{~s} ; \mathrm{DP}_{4}$, males: $7.510 \pm 0.691 \mathrm{~s}$; females: $7.151 \pm 0.740 \mathrm{~s}$; $\mathrm{DP}_{5}$, males: $9.329 \pm 0.507 \mathrm{~s}$; females: $8.945 \pm 0.935 \mathrm{~s}$; full versus null: $\chi^{2}=18,328.330, d f=4, p<0.001$; males versus females: estimate $=0.145, \mathrm{SE}=0.023, t$ value $=74.922, p<0.001$; Fig. 2b). In particular, the model including an interaction between sex and phrase type showed that phrases duration varied with both sex of the emitter and type of the phrase, for phrases including up to four units. However, we did not find differences in the duration of $\mathrm{DP}_{5}$ (full versus null: $\chi^{2}=18,448.360, d f=7, p<0.001$; Table 2; Fig. 2b).

\section{Unit duration}

We found that unit duration was influenced by phrase size, position within the phrase, and the sex of the emitter (full vs null: $\chi^{2}=11,315.51, d f=6, p<0.001$ ). In particular, we found that larger the phrase size, the shorter the units' duration (estimate $=-0.124, \mathrm{SE}=0.001, t$ value $=-99.570, p<0.001)$ and that male units were longer than female ones (estimate $=0.184, \mathrm{SE}=0.020, t$ value $=8.994, p<0.001)$. The model considering the interaction between sex and phrase type (full vs null model: $\left.\chi^{2}=11,677.690, d f=8, p<0.001\right)$ indicated that males emit longer units, regardless of the phrase size, in phrases including up to four units; we found no differences in the duration of units in phrases including five units (Fig. 3; Table3). Our results also indicated that the units showed a progressive increase in duration along the phrase (see Table 3; Fig. 3). Indeed, all units but the second unit of phrases including four and five units were longer than all previous ones, for all phrase types (Table 4, Fig. 3).

Finally, we found that the unit duration was not only influenced by their position in the phrase, the type of phrase, and the sex, but also by an interaction among all these factors (full vs null model: $\chi 2=13,907.600, d f=33$, $p<0.001)$. Our results indeed indicated that the duration of all units differed between the sexes (with males giving longer units than females), and according to their position in the phrase, for phrases including up to four units (see Online Resource 1). Still, only the last unit of phrases
Table 2 Results of the Tukey test for the effect of the descending phrase type (left) and for the interaction including sex and phrase type (right) on the phrase duration (Anderson-Darling Normality test: $A=43.608, p<0.001)$

\begin{tabular}{|c|c|c|c|c|c|c|c|c|c|}
\hline \multirow[t]{2}{*}{ Phrase type } & \multicolumn{4}{|c|}{ Phrase duration } & \multirow{2}{*}{$\begin{array}{l}\text { Phrase type* } \\
\text { sex }\end{array}$} & \multicolumn{4}{|c|}{ Phrase duration } \\
\hline & Estimate & SE & $z$ value & $p$ value & & Estimate & SE & $z$ value & $p$ value \\
\hline DP3-DP2 & 0.418 & 0.002 & 201.30 & $<0.001$ & DP2 (M vs F) & 0.160 & 0.017 & 9.086 & $<0.001$ \\
\hline DP4-DP2 & 0.706 & 0.003 & 202.81 & $<0.001$ & DP3 (M vs F) & 0.137 & 0.017 & 7.754 & $<0.001$ \\
\hline DP5-DP2 & 0.958 & 0.014 & 69.435 & $<0.001$ & DP4 (M vs F) & 0.087 & 0.01 & 4.709 & $<0.001$ \\
\hline DP4-DP3 & 0.288 & 0.003 & 83.49 & $<0.001$ & DP5 (M vs F) & 0.019 & 0.033 & 0.604 & 0.998 \\
\hline DP5-DP3 & -0.540 & 0.014 & 39.17 & $<0.001$ & - & - & - & - & - \\
\hline DP5-DP4 & 0.252 & 0.014 & 18.06 & $<0.001$ & - & - & - & - & - \\
\hline
\end{tabular}

Statistically significant values are indicated in bold

$M$ males, $F$ females, $D P 2$ Descending Phrase including two units, $D P 3$ Descending Phrase including three units, DP4 Descending Phrase including four units, DP5 Descending Phrase including five units

\begin{tabular}{|l|l|l|l|l|}
\hline Journal : Large 10071 & Article No : 1495 & Pages : 10 & MS Code : 1495 & Dispatch : 24-2-2021 \\
\hline
\end{tabular}


Fig. 3 Density plots showing the duration of the different units included in a phrase, for the different phrase types, for males and females. a Descending phrase including two units; b Descending phrase including three units; c Descending phrase including four units; $\mathbf{d}$ Descending phrase including five units. Plots were generated in $\mathrm{R}$, using the ggplot 2 package (Wickham 2016)

Table 3 Results of the Tukey test for the effect of the unit type (left) and for the interaction including sex and phrase type (right) on the unit duration (Anderson-Darling Normality test: $A=273.7, p<0.001$ )
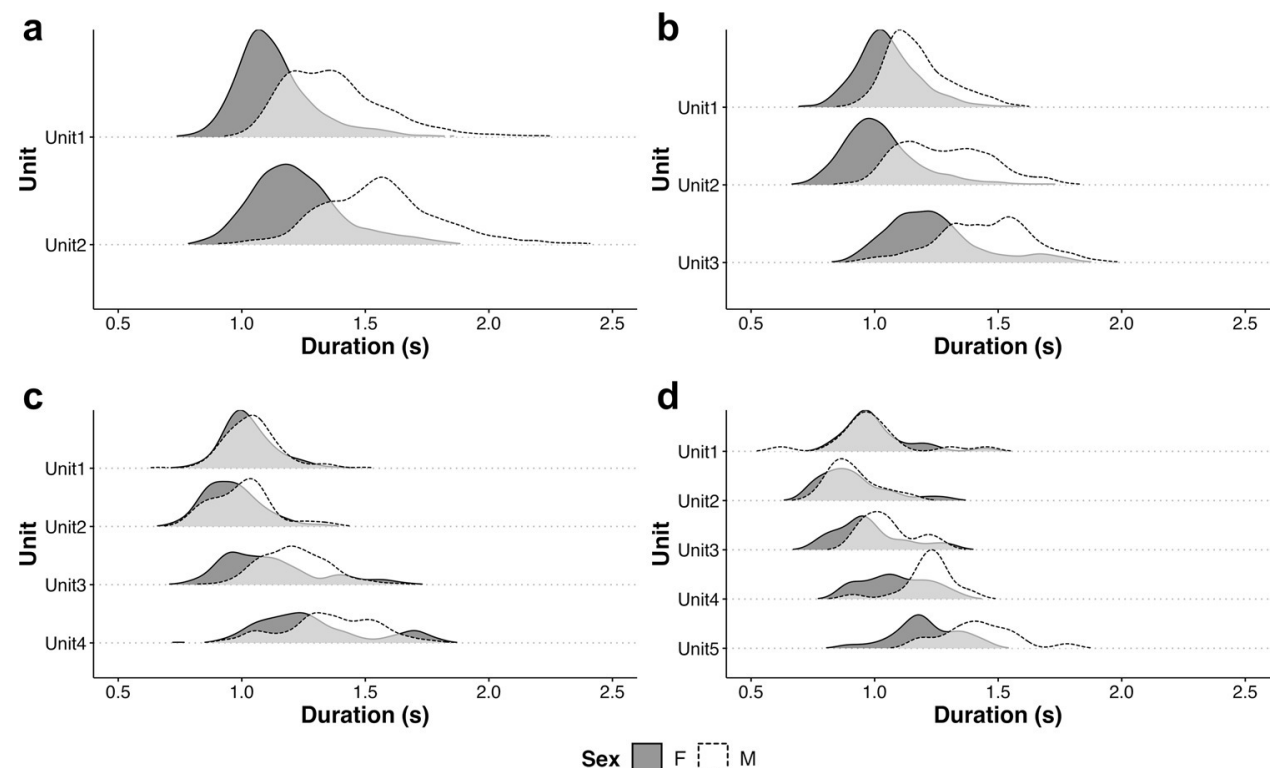

\begin{tabular}{|c|c|c|c|c|c|c|c|c|c|}
\hline \multirow[t]{2}{*}{ Unit type } & \multicolumn{4}{|c|}{ Unit duration } & \multirow{2}{*}{$\begin{array}{l}\text { Phrase type* } \\
\text { sex }\end{array}$} & \multicolumn{4}{|c|}{ Unit duration } \\
\hline & Estimate & SE & $z$ & $P$ & & Estimate & SE & $z$ & $P$ \\
\hline $2 \mathrm{nd}-1 \mathrm{st}$ & 0.048 & 0.001 & 29.841 & $<0.001$ & DP2 (M vs F) & 0.213 & 0.020 & 10.475 & $<0.001$ \\
\hline $3 \mathrm{rd}-1 \mathrm{st}$ & 0.017 & 0.002 & 86.766 & $<0.001$ & DP3 (M vs F) & 0.174 & 0.020 & 8.553 & $<0.001$ \\
\hline 4 th-1st & 0.299 & 0.004 & 74.482 & $<0.001$ & DP4 (M vs F) & 0.126 & 0.021 & 6.099 & $<0.001$ \\
\hline 5 th-1st & 0.434 & 0.017 & 26.014 & $<0.001$ & DP5 (M vs F) & 0.065 & 0.261 & 2.487 & 0.129 \\
\hline 3 rd-2nd & 0.129 & 0.002 & 63.205 & $<0.001$ & & & & & \\
\hline 4th-2nd & 0.251 & 0.004 & 62.519 & $<0.001$ & & & & & \\
\hline 5 th-2nd & 0.386 & 0.017 & 23.134 & $<0.001$ & & & & & \\
\hline 4th-3rd & 0.122 & 0.004 & 30.713 & $<0.001$ & & & & & \\
\hline 5 th-3rd & 0.257 & 0.017 & 15.445 & $<0.001$ & & & & & \\
\hline 5 th- 4 th & 0.135 & 0.017 & 8.006 & $<0.001$ & & & & & \\
\hline
\end{tabular}

Statistically significant values are indicated in bold

$M$ males, $F$ females, DP2 Descending Phrase including two units, DP3 Descending Phrase including three units, DP4 Descending Phrase including four units, DP5 Descending Phrase including five units. Unit Type indicates the position of the unit within the phrase (i.e., 1st is the first unit within the phrase) including five notes resulted sexually dimorphic (Table 4; Fig. 3).

\section{Discussion}

Our findings provide the first compelling evidence that the indris' songs follow both Zipf's law of brevity and the Menzerath-Altmann law. This study is the first report for adherence to linguistic laws in vocal sequences of a lemur species. In conformity to Zipf's principle, we found that an increase in the phrase size was negatively related to its occurrence. Indeed, phrases composed of two and three units tended to be included in the songs almost twice as often as phrases comprising four or five units. When controlling for the phrase duration, we also found that more common phrase types (DP2 and DP3) were shorter than the infrequent longer phrases. Our results are in line with previous findings on other primate species vocal (Formosan macaque: Semple et al. 2010, 2013) and gestural communication (western gorilla: Genty and Byrne 2010; chimpanzee: Heesen et al. 2019). This investigation, endorsing recent findings on gibbons (Huang et al. 2020), also corroborates evidence that primate songs conform to the Zipf's law of brevity and broadens findings on the prevalence of this feature in communication systems. We indeed demonstrated that, unlike geladas (Gustison et al. 2016) and bats (Luo et al. 2013), where Zip's law of brevity characterizes short-range

\begin{tabular}{|l|l|l|l|l|}
\hline Journal : Large 10071 & Article No : 1495 & Pages : 10 & MS Code : 1495 & Dispatch : 24-2-2021 \\
\hline
\end{tabular}


Table 4 Results of the Tukey post hoc test for the interaction including sex, phrase type, and unit position

\begin{tabular}{|c|c|c|c|c|c|c|}
\hline & Phrase type & $\begin{array}{l}\text { Unit type } \\
\text { (mean duration } \pm \mathrm{SD})\end{array}$ & Estimate & SE & $z$ value & $P$ value \\
\hline \multirow[t]{14}{*}{ Males vs females } & \multirow{2}{*}{$\mathrm{DP}_{2}$} & $1 \mathrm{st}(1.249 \pm 0.210 \mathrm{~s})$ & 0.186 & 0.020 & 9.096 & $<0.001$ \\
\hline & & 2nd $(1.385 \pm 0.284 \mathrm{~s})$ & 0.240 & 0.020 & 11.719 & $<0.001$ \\
\hline & \multirow[t]{3}{*}{$\mathrm{DP}_{3}$} & $1 \mathrm{st}(1.109 \pm 0.146 \mathrm{~s})$ & 0.118 & 0.020 & 5.747 & $<0.001$ \\
\hline & & 2nd $(1.141 \pm 0.215 \mathrm{~s})$ & 0.233 & 0.020 & 11.377 & $<0.001$ \\
\hline & & $3 \mathrm{rd}(1.329 \pm 0.224 \mathrm{~s})$ & 0.170 & 0.020 & 8.289 & $<0.001$ \\
\hline & \multirow[t]{4}{*}{$\mathrm{DP}_{4}$} & $1 \mathrm{st}(1.033 \pm 0.110 \mathrm{~s})$ & 0.089 & 0.021 & 4.132 & $<0.001$ \\
\hline & & 2nd $(0.975 \pm 0.123 \mathrm{~s})$ & 0.117 & 0.021 & 5.425 & $<0.001$ \\
\hline & & $3 \mathrm{rd}(1.148 \pm 0.185 \mathrm{~s})$ & 0.169 & 0.021 & 7.852 & $<0.001$ \\
\hline & & 4 th $(1.310 \pm 0.219 \mathrm{~s})$ & 0.131 & 0.021 & 6.072 & $<0.001$ \\
\hline & \multirow[t]{5}{*}{$\mathrm{DP}_{5}$} & $1 \mathrm{st}(1.000 \pm 0.152 \mathrm{~s})$ & -0.025 & 0.038 & -0.677 & 1.000 \\
\hline & & 2nd $(0.910 \pm 0.121 \mathrm{~s})$ & 0.003 & 0.038 & 0.084 & 1.000 \\
\hline & & $3 \mathrm{rd}(1.008 \pm 0.133 \mathrm{~s})$ & 0.076 & 0.038 & 2.017 & 0.922 \\
\hline & & 4th $(1.140 \pm 0.138 \mathrm{~s})$ & 0.114 & 0.038 & 3.011 & 0.213 \\
\hline & & 5 th $(1.294 \pm 0.174 \mathrm{~s})$ & 0.157 & 0.038 & 4.154 & $<0.001$ \\
\hline
\end{tabular}

Statistically significant values are indicated in bold

$M$ males, $F$ females, DP2 Descending Phrase including two units, DP3 Descending Phrase including three units, DP4 Descending Phrase including four units, DP5 Descending Phrase including five units. Unit Type (for which we reported mean duration \pm standard deviation) indicates the position of the unit within the phrase (i.e., 1st is the first unit within the phrase) vocalizations, this persists in long-distance communication as well, as found in two crested gibbon species whose loud morning call encompasses compression rules and follows Zipf's law of brevity (Huang et al. 2020). In line with Menzerath-Altmann law (1980), we found a negative relationship between the number of units included in a phrase and their duration, showing a trade-off between the duration of the construction and of its constituents. Such a kind of compensation is in line with a growing body of evidence regarding different species vocal behavior (banded penguins: Favaro et al. 2020; geladas: Gustison et al. 2016, chimpanzees: Fedurek et al. 2017; Bornean gibbon: Clink et al. 2020a, b; Cao-vit gibbon, western black-crested gibbon: Huang et al. 2020). The adherence to Menzerath-Altmann Law can be either the result of a selection for coding efficiency (Gustison et al. 2016) or it may depend on mechanical constraints on vocal production (Clink et al. 2020a, b), while compression (Bezerra et al. 2011) has been hypothesized to be the result of two pressures: accuracy (ambiguity avoidance) and efficiency (Ferrer-i-Cancho et al. 2020). In indris, (i) the emission of phrases with more units seems to only be possible as long as the duration of a phrase is balanced with that of its units and (ii) we demonstrated that indris reduce the length of their phonation (i.e., the portion of the song sang) at the increase of the song duration (De Gregorio et al. 2019). Finally, as reported in humans (Lindblom and Sundberg 2007) and two crested gibbon species (Huang et al. 2020), indris increased the duration of the units towards the very end of a phrase and, as recently suggested, the duration of a given unit may reflect breathing constraints related to the emission of previous ones (Favaro et al. 2020). The shortening of units at the beginning of a sequence, therefore, may allow indris to avoid breathing constraints, as hypothesized for gibbons (Huang et al. 2020).

Furthermore, despite being focused on a subset of the vocal repertoire, our findings provide evidence that, at least at the phrase level, indris' songs sustain principles of vocal compression and, if on one hand physical constraints may impact signal duration, on the other hand, signal redundancy may allow indris to overcome loss of information due to signal compression. Indeed, redundancy maximization can represent a potential alternative to compression where the pressure for compression can cause a signal to be more sensitive to noise (Ferrer-i-Cancho et al. 2013). As gibbons' solo bouts, indri songs consist of a repetition of phrases and, as proposed for Nomascus gibbons, signal redundancy may compensate the loss of information generated by compression (Huang et al. 2020). The role of environmental features in forging the acoustic characteristics of signals and in influencing their perception has long been hypothesized (Marler 1967) and indeed natural selection favors signal structure and signaling strategies that maximize signals transmission while minimizing their degradation (Endler 1992). Indris use songs to mediate long-distance communication, in particular, to actively defend their territories (Torti et al. 2013; Bonadonna et al. 2017). We can conclude that song structure is likely to be adapted to the environment of emission. Different strategies have been proposed to cope with acoustic interference related to environmental features (Waser and Brown 1986). For example, noise-induced vocal adjustments

\begin{tabular}{|l|l|l|l|l|}
\hline Journal : Large 10071 & Article No : 1495 & Pages : 10 & MS Code : 1495 & Dispatch : 24-2-2021 \\
\hline
\end{tabular}


(common marmoset: Roy et al. 2011; cotton-top tamarin: Egnor and Hauser 2006), antiphonal calling, or redundant structures (Roy et al. 2011). Combining units into sequences may increase communication capacity (Plotkin and Nowak 2000): in indris, the combination of signal duration compression with phrases redundancy may represent a strategy to maximize signal transmission, and therefore, their longdistance communication is likely to be a balance between compression and efficacy. Moreover, indris' songs are loud calls given by multiple callers at the same time that can be used to convey information about sex (Gamba et al. 2016; De Gregorio et al. 2019), age (De Gregorio et al. in preparation), and individuality of the emitters (Torti et al. 2017). Songs can also vehiculate information about the individuals' reproductive status (Gamba et al. 2016), and are supposed to mediate mate attraction and pair formation at a distance (Torti et al. 2013).

On the one hand, as proposed for common marmosets, the persistent repetition of phrases guarantees the information redundancy (Roy et al. 2011). It allows avoiding the overlap with other individuals, which is crucial for non-reproductive indris to increase their chance to broadcast individuality and unpaired status (Gamba et al. 2016). On the other hand, the trade-off between units and phrases duration we found in males and females can represent the result of pressures acting on both sexes to ensure signal vehiculation (Favaro et al. 2020). Hence, we suggest that indris, as hypothesized for geladas (Gustison et al. 2016), chimpanzees (Fedurek et al. 2017) and gibbons (Clink et al. 2020a, b; Huang et al. 2020) cannot produce long phrases and long notes at the same time. Still, rather than being the sole product of selection for coding efficacy, their vocal production is the result of a compromise among the need to ensure signal transmission, the need to reduce energetic costs of producing an extended vocal sequence (i.e., marmoset vocal production; Ghazanfar et al. 2019), and limitations due to mechanical constraints on breathing control (MacLarnon and Hewitt 1999; Hewitt et al. 2002), as hypothesized for chimpanzees (Fedurek et al. 2017)

In conclusion, this study represents the first evidence of adherence to Zipf's law of brevity and Menzerath-Altmann law in the vocal behavior of a prosimian, a further dowel among those corroborating that selective pressures for compression are shared among different vocal communication systems (Ferrer-i-Cancho et al. 2013). Our results indicate that these features, previously demonstrated in humans, apes, and monkeys, characterize strepsirrhine vocal production as well. Therefore, selective pressures for vocal compression might be more ancestral than previously thought, within the order Primates.

Supplementary Information The online version contains supplementary material available at https://doi.org/10.1007/s10071-021-01495-3.
Acknowledgments This research was supported by Università degli Studi di Torino and by grants from the Parco Natura Viva-Garda Zoological Park. We are grateful to Cesare Avesani Zaborra and Caterina Spiezio for their support. We also thank the GERP (Groupe d'Étude et de Recherche sur les Primates de Madagascar) for the field logistics organization and to both field guides and assistants helping during the data collection.

Author contributions DV and MG conceived the study design and the methodology; VT, DV, CDG, AZ, and TR collected the data; DV and MG conducted the formal analysis and investigation; DV wrote the manuscript, all authors edited the manuscript and approved its final version.

Data availability Data used in this study can be found at https://githu b.com/sciabola/ANCO2021_DATA

\section{Declarations}

Conflict of interest The authors declare no conflict of interest.

Ethical approval Research permits for this research have been granted from Direction des Eaux et Forêts and 'Madagascar National Parks' (formerly ANGAP). 2004: N190/MINENV.EF/SG/DGEF/ DPB/ SCBLF/RECH; 2005: N197/MINENV.EF/SG/DGEF/DPB/SCBLF/ RECH; 2006: N172/06/ MINENV.EF/SG/DGEF/DPB/SCBLF; 2007: N0220/07/MINENV.EF/SG/DGEF/DPSAP/SSE; 2008: N258/08/ MEFT/SG/DGEF/DSAP/SSE; 2009: N243/09/MEF/SG/DGF/DCB. SAP/SLRSE; 2010: N118/10/MEF/SG/DGF/DCB.SAP/SCBSE and 293/10/MEF/SG/DGF/DCB.SAP/SCB; 2011: N274/11/MEF/SG/DGF/ DCB.SAP/SCB; 2012: N245/12/MEF/ SG/DGF/DCB.SAP/SCB; 2013: permit not required as data collection was performed by Malagasy citizens only. 2014: N066/14/MEF/SG/DGF/DCB.SAP/SCB; 2015: N180/15/MEEMF/SG/DGF/DAPT/SCBT; 2016: N98/16/MEEMF/ SG/DGF/DAPT/SCB.Re and N217/16/MEEMF/SG/DGF/DSAP/SCB. Re; 2017: 73/17/MEEF/SG/DGF/DSAP/SCB.RE; 2018: 91/18/MEEF/ SG/DGF/DSAP/SCB.Re; 2019: 118/19/MEDD/SG/DGEF/DSAP/ DGRNE and 284/19/MEDD/SG/DGEF/DSAP/DGRNE; 2019/2020: 338/19/MEDD/SG/DGEF/DSAP/DGRNE. Approval for observational researches and for studies that do not involve animal handling are not required by our institutional committees.

\section{References}

Altmann J (1974) Observational study of behavior: sampling methods. Behaviour 49:227-267. https://doi.org/10.1163/156853974X 00534

Altmann G (1980) Prolegomena to Menzerath's law. Glottometrika $2: 1-10$

Barr DJ, Levy R, Scheepers C, Tily HJ (2013) Random effects structure for confirmatory hypothesis testing: keep it maximal. J Mem Lang 68:255-278. https://doi.org/10.1016/j.jml.2012.11.001

Bates D, Mächler M, Bolker B, Walker S (2015) Fitting linear mixedeffects models using lme4. J Stat Softw 67:1-48

Bezerra BM, Souto AS, Radford AN, Jones G (2011) Brevity is not always a virtue in primate communication. Biol Lett 7:23-25

Boersma P, Weenink D (2017) Praat: Doing phonetics by computer [Computer Program]. Version 6.0.28. http://www.praat.org. Accessed 23 Mar 2017

Bonadonna G, Torti V, Randrianarison RM, Martinet N, Gamba M, Giacoma C (2014) Behavioral correlates of extra-pair 
copulation in Indri indri. Primates 55(1):119-123. https://doi. org/10.1007/s10329-013-0376-0

Bonadonna G, Torti V, Sorrentino V, Randrianarison RM, Zaccagno M, Gamba M, Giacoma C (2017) Territory exclusivity and intergroup encounters in the indris (Mammalia: Primates: Indridae: Indri indri) upon methodological tuning. Eur Zool J 84:238-251. https://doi.org/10.1080/24750263.2017.1318184

Bonadonna G, Torti V, De Gregorio C, Valente D, Randrianarison RM, Pozzi L, Gamba M, Giacoma C (2019) Evidence of genetic monogamy in the lemur Indri (Indri indri). Am J Primatol 81(6):e22993. https://doi.org/10.1002/ajp.22993

Bonadonna G, Zaccagno M, Torti V, Valente D, De Gregorio C, Randrianarison RM, Tan C, Gamba M, Giacoma C (2020) Intraand intergroup spatial dynamics of a pair-living singing primate, Indri indri: a multiannual study of three Indri groups in Maromizaha Forest, Madagascar. Int J Primatol 41:1-22. https://doi. org/10.1007/s10764-019-00127-5

Bretz F, Hothorn T, Westfall P (2010) Multiple comparisons using R. Chapman \& Hall/CRC Press, Boca Raton

Briseño-Jaramillo M, Ramos-Fernandez G, Palacios-Romo TM, Sosa-López JR, Lemasson A (2018) Age and social affinity effects on contact call interactions in free-ranging spider monkeys. Behav Ecol Sociobiol 72:192. https://doi.org/10.1007/ s00265-018-2615-2

Cäsar C, Zuberbühler K (2012) Referential alarm calling behaviour in New World primates. Curr Zool 58(5):680-697. https://doi. org/10.1093/czoolo/58.5.680

Clay Z, Zuberbühler K (2009) Food-associated calling sequences in bonobos. Anim Behav 77:1387-1396. https://doi.org/10.1016/j. anbehav.2009.02.016

Clink DJ, Tasirin JS, Klinck H (2020a) Vocal individuality and rhythm in male and female duet contributions of a nonhuman primate. Curr Zool 66(2):173-186. https://doi.org/10.1093/cz/ zoz035

Clink DJ, Ahmad AH, Klinck H (2020b) Brevity is not a universal in animal communication: evidence for compression depends on the unit of analysis in small ape vocalizations. R Soc Open Sci 7:200151. https://doi.org/10.1098/rsos.200151

De Gregorio C, Zanoli A, Valente D, Torti V, Bonadonna G, Randrianarison RM, Giacoma C, Gamba M (2019) Female indris determine the rhythmic structure of the song and sustain a higher cost when the chorus size increases. Curr Zool 65(1):89-97. https ://doi.org/10.1093/cz/zoy058

De Gregorio C, Carugati F, Estienne V, Valente D, Raimondi T, Torti V, Miaretsoa L, Ratsimbazafy J, Gamba M and Giacoma C (2021) Born to sing! Song development in a singing primate. Curr Zool CZ-2020-0306.R1

Demartsev V, Gordon N, Barocas A, Bar-Ziv E, Ilany T, Goll Y, Ilany A, Geffen E (2019) The 'Law of Brevity' in animal communication: sex-specific signaling optimization is determined by call amplitude rather than duration. Evol Lett 3:623-634. https://doi. org/10.1002/evl3.147

Dobson AJ (2002) An introduction to generalized linear models. CRC Press, Boca Raton

Egnor SER, Hauser MD (2006) Noise-induced vocal modulation in cotton-top tamarins (Saguinus oedipus). Am J Primatol 68(12):11831190. https://doi.org/10.1002/ajp.20317

Endler A (1992) Signals, signal conditions, and the direction of evolution. Am Nat 139(1):125-153. https://doi.org/10.1086/285308

Favaro L, Gamba M, Cresta E, Fumagalli E, Bandoli F, Pilenga C, Isaja V, Mathevon N, Reby D (2020) Do penguins' vocal sequences conform to linguistic laws? Biol Lett 16:20190589. https://doi. org/10.1098/rsbl.2019.0589

Fedurek P, Slocombe KE (2011) Primate vocal communication: a useful tool for understanding human speech and language evolution? Hum Biol 83(2):153-173. https://doi.org/10.3378/027.083.0202
Fedurek P, Zuberbühler K, Semple S (2017) Trade-offs in the production of animal vocal sequences: insights from the structure of wild chimpanzee pant hoots. Front Zool 14:50. https://doi.org/10.1186/ s12983-017-0235-8

Ferrer-i-Cancho R, Hernández-Fernández A (2013) The failure of the law of brevity in two New World primates. Statistical caveats. Glottotheory Int J Theor Linguist 4:45-55. https://doi. org/10.1524/glot.2013.0004

Ferrer-i-Cancho R, Lusseau D (2009) Efficient coding in dolphin surface behavioral patterns. Complexity 14(5):23-25. https://doi. org/10.1002/cplx.20266

Ferrer-i-Cancho R, McCowan B (2012) The span of correlations in dolphin whistle sequences. J Stat Mech Theory Exp. https://doi. org/10.1088/1742-5468/2012/06/p06002

Ferrer-i-Cancho R, Hernández-Fernández A, Lusseau D, Agoramoorthy G, Hsu MJ, Semple S (2013) Compression as a universal principle of Animal behavior. Cogn Sci 37:1565-1578. https://doi. org/10.1111/cogs.12061

Ferrer-i-Cancho R, Bentz C, Seguin C (2020) Optimal Coding and the Origins of Zipfian Laws. J Quant Linguist. https://doi. org/10.1080/09296174.2020.1778387

Fox J, Weisberg S (2011) An R companion to applied regression, 2nd edn. SAGE Publications Inc, Thousand Oaks

Freeberg TM, Lucas JR (2012) Information theoretical approaches to chick-a-dee calls of Carolina chickadees (Poecile carolinensis). J Comp Psychol 126:68. https://doi.org/10.1037/a0024906

Gamba M, Favaro L, Torti V, Sorrentino V, Giacoma C (2011) Vocal tract flexibility and variation in the vocal output in wild indris. Bioacoustics 20:251-265. https://doi.org/10.1080/09524 622.2011 .9753649

Gamba M, Torti V, Estienne V, Randrianarison RM, Valente D, Rovara P, Bonadonna G, Friard O, Giacoma C (2016) The indris have got rhythm! Timing and pitch variation of a primate song examined between sexes and age classes. Front Neurosci 10:249. https://doi. org/10.3389/fnins.2016.00249

Geissmann T (2000) Gibbon songs and human music from an evolutionary perspective. In: Wallin NL, Merker B, Brown S (eds) The origins of music. MIT Press, Cambridge, pp 103-123

Genty E, Byrne RW (2010) Why do gorillas make sequences of gestures? Anim Cogn 13:287-301. https://doi.org/10.1007/s1007 1-009-0266-4

Ghazanfar AA, Liao DA, Takahasi DY (2019) Volition and learning in primate vocal behaviour. Anim Behav 151:239-247. https://doi. org/10.1016/j.anbehav.2019.01.021

Giacoma C, Sorrentino V, Rabarivola C, Gamba M (2010) Sex differences in the song of Indri indri. Int J Primatol 31:539-551. https ://doi.org/10.1007/s10764-010-9412-8

Glazko GV, Nei M (2003) Estimation of divergence times for major lineages of primate species. Mol Biol Evol 20(3):424-434. https ://doi.org/10.1093/molbev/msg050

Gustison ML, Semple S, Ferrer-i-Cancho R, Bergman TJ (2016) Gelada vocal sequences follow Menzerath's linguistic law. Proc Natl Acad Sci USA 113(19):2750-2758. https://doi.org/10.1073/ pnas. 1522072113

Haimoff EH (1986) Convergence in the duetting of monogamous Old World primates. J Hum Evol 15:51-59. https://doi.org/10.1016/ S0047-2484(86)80065-3

Heesen R, Hobaiter C, Ferrer-i-Cancho R, Semple S (2019) Linguistic laws in chimpanzee gestural communication. Proc R Soc B 286:20182900. https://doi.org/10.1098/rspb.2018.2900

Herrera JP, Dávalos LM (2016) Phylogeny and divergence times of lemurs inferred with recent and ancient fossils in the tree. Syst Biol 65(5):772-791. https://doi.org/10.1093/sysbio/syw035

Hewitt G, MacLarnon A, Jones KE (2002) The functions of laryngeal air sacs in primates: a new hypothesis. Folia Primatol 73:70-94. https://doi.org/10.1159/000064786 
Huang M, Ma H, Ma C, Garber PA, Fan P (2020) Male gibbon loud morning calls conform to Zipf's law of brevity and Menzerath's law: insights into the origin of human language. Anim Behav 160:145-155. https://doi.org/10.1016/j.anbehav.2019.11.017

Katsu N, Yamada K, Okanoya K, Nakamichi M (2019) Temporal adjustment of short calls according to a partner during vocal turntaking in Japanese macaques. Curr Zool 65(1):99-105. https://doi. org/10.1093/cz/zoy077

Kershenbaum A, Blumstein DT, Roch MA et al (2016) Acoustic sequences in non-human animals: a tutorial review and prospectus. Biol Rev 91:13-52. https://doi.org/10.1111/brv.12160

Leroux M, Townsend S (2020) Call Combinations in great apes and the evolution of syntax. Anim Behav Cogn 7(2):131-139

Lindblom B, Sundberg J (2007) The human voice in speech and singing. In: Rossing TD (ed) Springer handbook of acoustics. Springer-Verlag, New York, pp 669-712

Luo B, Jiang T, Liu Y, Wang J, Lin A, Wei X, Feng J (2013) Brevity is prevalent in bat short-range communication. J Comp Physiol A 199:325-333. https://doi.org/10.1007/s00359-013-0793-y

MacLarnon AM, Hewitt GP (1999) The evolution of human speech: the role of enhanced breathing control. Am J Phys Anthropol 109:341-363. https://doi.org/10.1002/(SICI)1096-8644(19990 7) $109: 3 \% 3 \mathrm{c} 341::$ AID-AJPA5\%3e3.0.CO;2-2

Marler P (1967) Animal communication signals. Science 157:769-774. https://doi.org/10.1126/science.157.3790.769

Ouattara K, Lemasson A, Zuberbühler K (2009) Campbell's monkeys concatenate vocalizations into context-specific call sequences. Proc Natl Acad Sci USA 106(51):22026-22031. https://doi. org/10.1073/pnas.0908118106

Piantadosi ST, Tily H, Gibson E (2011) Word lengths are optimized for efficient communication. Proc Natl Acad Sci USA 108(9):35263529. https://doi.org/10.1073/pnas.1012551108

Plotkin JB, Nowak MA (2000) Language evolution and information theory. J Theor Biol 205(1):147-159. https://doi.org/10.1006/ jtbi.2000.2053

Pollock JI (1986) The song of the Indris (Indri indri; Primates: Lemuroidea): natural history, form and function. Int J Primatol 7:225-267. https://doi.org/10.1007/BF02736391

R Core Team (2019). R: a language and environment for statistical computing. R Foundation for Statistical Computing, Vienna, Austria. https://www.R-project.org/

Roy S, Miller C, Gottsch D, Wang X (2011) Vocal control by the common marmoset in the presence of interfering noise. J Exp Biol 214:3619-3629. https://doi.org/10.1242/jeb.056101

Savage P, Brown S, Sakai E, Currie T (2015) Statistical universals reveal the structures and functions of human music. Proc Natl Acad Sci USA 112(29):8987

Semple S, Hsu MJ, Agoramoorthy G (2010) Efficiency of coding in macaque vocal communication. Biol Lett 6:469-471. https://doi. org/10.1098/rsbl.2009.1062

Semple S, Hsu MJ, Agoramoorthy G, Ferrer-i-Cancho R (2013) The law of brevity in macaque vocal communication is not an artefact of analysing mean call durations. J Quant Linguist 20(3):209-217. https://doi.org/10.1080/09296174.2013.799917

Slocombe KE, Zuberbühler K (2005) Functionally referential communication in a chimpanzee. Curr Biol 15(19):1779-1784. https ://doi.org/10.1016/j.cub.2005.08.068
Sorrentino V, Gamba M, Giacoma C (2013) A quantitative description of the vocal types emitted in the Indri's song. In: Masters J, Gamba M, Génin F (eds) Leaping ahead: advances in Prosimian biology. Springer Science + Business Media, New York, pp $315-322$

Strauss U, Grzybek P, Altmann G (2007) Word length and word frequency. In: Grzybek P (ed) Contributions to the science of text and language. Springer, Dordrecht, The Netherlands, pp 277-294

Sueur J, Aubin SC (2008) Seewave: a free modular tool for sound analysis and synthesis. Bioacoustics 18:213-226. https://doi. org/10.1080/09524622.2008.9753600

Thalmann U, Geissmann T, Simona A, Mutschler T (1993) The indris of Anjanaharibe-Sud, northeastern Madagascar. Int J Primatol 14:357-381. https://doi.org/10.1007/BF02192772

Torti V, Gamba M, Rabemananjara ZH, Giacoma C (2013) The songs of the indris (Mammalia: Primates: Indridae): contextual variation in the long-distance calls of a lemur. Ital J Zool 80:596-607. https ://doi.org/10.1080/11250003.2013.845261

Torti V, Bonadonna G, De Gregorio C, Valente D, Randrianarison RM, Friard O, Giacoma C (2017) An intra-population analysis of the indris' song dissimilarity in the light of genetic distance. Sci Rep 7:10140. https://doi.org/10.1038/s41598-017-10656-9

Torti V, Valente D, De Gregorio C, Comazzi C, Miaretsoa L, Ratsimbazafy J, Giacoma C, Gamba M (2018) Call and be counted! Can we reliably estimate the number of callers in the indri's (Indri indri) song? PLoS ONE 13(8):e0201664. https://doi.org/10.1371/ journal.pone.0201664

Waser PM, Brown CH (1986) Habitat acoustics and primate communication. Am J Primatol 10(2):135-154. https://doi.org/10.1002/ ajp.1350100205

Watson SK, Heesen R, Hedwig D, Robbins MM, Townsend SW (2020) An exploration of Menzerath's law in wild mountain gorilla vocal sequences. Biol Lett 16:20200380. https://doi.org/10.1098/ rsbl.2020.0380

Wickham H (2016) ggplot2: elegant graphics for data analysis. Springer-Verlag, New York

Zanoli A, De Gregorio C, Valente D, Torti V, Bonadonna G, Randrianarison RM, Giacoma C, Gamba M (2020) Sexually dimorphic phrase organization in the song of the indris (Indri indri). Am J Primatol 82:e23132. https://doi.org/10.1002/ajp.23132

Zipf GK (1936) The Psycho-biology of language: an introduction to dynamic philology. George Routledge and Sons Ltd, London

Zipf GK (1945) The meaning-frequency relationship of words. J Gen Psychol 33:251-256

Zipf GK (1949) Human behavior and the principle of least effort. An introduction to human ecology. Hafner Publishing Company, New York and London

Publisher's Note Springer Nature remains neutral with regard to jurisdictional claims in published maps and institutional affiliations. 